\title{
Utilization of Crumb Rubber in Flexible Pavements
}

\author{
Rutuja Sathe, Deven Ramole, Milind Khanande ${ }^{1}$, Suraj. V. Bhise ${ }^{2}$ and Sachin M. Pore ${ }^{3}$ \\ Department of Civil Engineering, \\ Dr Babasaheb Ambedkar Technological University, India
}

\begin{abstract}
India's waste tyres account for about 6-7\% of the global total. With the local tyre industry growing at $12 \%$ per annum, waste volumes are rising. India has been recycling and reusing waste tyres for four decades, although it is estimated that $60 \%$ are disposed of through illegal dumping. Modern tyres are fundamentally rubber products; they are a complex mix of natural and synthetic rubbers, and various structural reinforcing elements including metals and chemical additives. This complexity has led to stockpiling, dumping and diversion to landfill. This has exposed communities to environmental and health risks and has squandered valuable resources locked up in tyre dumps. Stockpiled tyres are at risk of fire and toxic smoke; other risks include the stagnant water in tyres that provides breeding grounds for mosquitoes and leaching of toxic substances into soils. India is the second largest producer of reclaim rubber after China. In 2011, India produced 90,000 metric tonnes of reclaimed rubber from waste tyres. We have developed Crumb Rubber Modified Bitumen which introduces a simple modification into the conventional manufacturing process for bitumen.
\end{abstract}

Keywords - Stockpiling, Stagnant Water, Synthetic Rubber, Waste tire, CRMB

\section{INTRODUCTION}

Bituminous pavement has a poor susceptibility due to water, heat and axle load. Its solution is modified bitumen which is made by crumb rubber plus bitumen. Crumb Rubber is the scrap tyre shredded into small pieces by the help of mechanical blades up to sizes of $1 \mathrm{~mm}-75 \mu \mathrm{m}$. CRMB was developed by Charles McDonald, an engineer with City of Phoenix, Arizona, US development in 1960s. Crumb Rubber is obtained from truck or automobile tyres. Whole truck tyre contains $18 \%$ of natural rubber compared to 9 percent in automobile tyre. It is produced from discarded rubber by two methods i.e. ambient grinding and Cryogenic grinding. There are two methods to mix tyre in bitumen one is Dry process and second is Wet process. Dry process is introduced by two Swedish companies. In this process Crumb rubber is used as a substitute for a part of mineral aggregate. However in wet process the crumb rubber is thoroughly mixing with bitumen and allowing it to react for a period of 45-1 hour. High temperature should be maintained.

\section{A. History of Using Crumb Rubber as a Modifier in Bituminous Pavement}

Incorporation of crumb rubber with conventional bitumen has been practiced for more than a century. The first attempt was taken in early 1840s, which involved mixing of natural rubber with bitumen to improve the desired engineering properties. Modification process of bitumen by natural and synthetic rubber was introduced at early 1843 (Thompson, 1979). The modification process both by natural and synthetic got further improvement in 1923 (Isacsson and Lu 1999; Yildrim, 2007). Yildrim stated that the development of rubber bitumen materials being used as joint sealers and patches began in the late 1930s.

According to the study of Hanson, in 1950 the use of scrap tire in asphalt pavement was reported (Hanson, Foo, Brown\& Denson 1994).

In 1960, Charlie Mac Donald reported successful use of scrap tyre rubber as an additive in bitumen binder modification. He concluded that after mixing of crumb rubber with the neat bitumen and allowing it to blend for mix duration of 45 to $60 \mathrm{~min}$, there were new material properties produced, which resulted in swelling in the size of the rubber particles at higher temperatures allowing for higher concentrations of liquid bitumen contents in pavement mixes (Huffman, 1980). In the mid-1980s, the Europeans began the development of different polymers and additives for application in bitumen binder modification (Brule, 1996).In recent years; the use of crumb rubber has gained interest in pavement modification and has shown that crumb tyre rubber can improve the bitumen performance properties (Brown, Jared, Jones\& Watson 1997).It is reported that during the bitumen-rubber thermal blending, due to higher stiffness and tensile strength at elevated temperatures, the modified bitumen had decreased rutting capability (Palit, Sudhakar \& Pandey, 2004).

\section{B. $\quad$ Material Collected}

Crumb rubber collected from a local tire re-treading shop near lonere, DBATU University was used to modify 80/100 penetration graded asphalt obtained from Public Works Department laboratory located in Mangaon. The crumb rubber was generated by scrapping old tyres of automobiles with use of buffing machine. Crumb rubber passing from $30 \mathrm{~mm}$ sieve and retain on $50 \mathrm{~mm}$ sieve was used. Ductility test, Penetration test were conducted on plain bitumen.

\section{LITERATURE REVIEW}

\section{A. International Journal of Engineering Research \&} Technology (IJERT)

V. Suganpriya, S. Omprakash, V. Chandralega presented their research in this paper titled 'Study of Behaviour of Bitumen Modified with Crumb Rubber'. The aim of the study was to utilize the waste materials i.e. crumb rubber waste for mass scale utilization such as in highway 
construction in an environmental safe manner. As a first part of this study, an attempt was made to assess the stabilization of the bitumen containing crumb rubber waste in shredded form by performing basic tests such as Penetration Test, Ductility Test, Softening Point Test, Viscosity Test and Flash \& Fire Point Tests. On the basis of the performance of the modified bitumen, the range of optimum percentages of crumb rubber

\section{B. International Journal of the Physical Sciences Vol. 7(2), pp. 166 - 170, 9 January, 2012}

Nuha S. Mashaan, Asim Hassan Ali, Mohamed Rehan Karim and Mahrez Abdel Aziz presented their research in this paper titled 'An overview of crumb rubber modified asphalt'. This review study presented the application of crumb rubber modifier in the asphalt modification of flexible pavement. From the results of previous studies, it aspires to consider crumb rubber modifier in hot mix asphalt to improve resistance to rutting and produce pavements with better durability by minimizing the distresses caused in hot mix asphalt pavement. Hence, road users would be ensured of safer and smoother roads. Waste was selected for further investigations.

\section{International Journal of Recent Technology and Engineering (IJRTE) ISSN: 2277-3878, Volume-8, Issue-1, May 2019}

Hanumantharao, Anil Pradhyumna, Durga Prasad, Naveen Kumar, Shantha Kumar Reddy, Hemanth Vardhan, presented their research in this paper titled 'Crumb Rubber Modified Bitumen and Quarry Dust in Flexible Pavements'. The comparison of pure bitumen and modified bitumen using waste crumb rubber is studied experimentally and discussed about the resistance against fatigue cracks, rutting cracks, strength of bitumen road and durability of modified bitumen at both high temperatures and low temperatures using "Marshall Stability Analysis". The quarry dust, which is another waste generating from the quarries, is used as fine aggregate and filler. $15 \%$ of $20 \mathrm{~mm}, 25 \%$ of $12.5 \mathrm{~mm}$, and $15 \%$ of $6 \mathrm{~mm}$ as coarse aggregate and $45 \%$ of quarry dust as fine aggregate and filler material is used. Waste crumb rubber materials are added to pure bitumen using wet process with percentage of $5 \%, 10 \%, 15 \%$ and $20 \%$ crumb rubber with size of $0.300 \mathrm{~mm}$ to $0.150 \mathrm{~mm}$. Laboratory results indicated the crumb rubber can incur high elastic behaviour, low penetration and high softening point compared to pure bitumen. Also high stability and flow values of modified bitumen compared to pure bitumen concrete mix at both low and high temperatures.

\section{METHODOLOGY}

\section{A. Tests Conducted}

1) Penetration Test: It measures the hardness or softness of bitumen by measuring the depth in tenths of millimeter to

which a standard loaded needle will penetrate vertically in 5 seconds. BIS had standardized the equipment and test procedure. The penetrometer consists of needle assembly with total weight of $100 \mathrm{~g}$ and a device for releasing and locking in any position. The bitumen is softened to a pouring consistency, stirred thoroughly and poured into containers at a depth at least $15 \mathrm{~mm}$ in excess of the expected penetration. The test should be conducted at a specified temperature of $25^{\circ} \mathrm{C}$.

Equipment used: Mould 1(8.3cmDia.), Mould 2(6cmDia), Penetrometer (Digital), Needle, Digital timer, Lubrication oil, Benzene (cleaning purpose).

2) Ductility Test: Ductility is the property of bitumen that permits it to undergo great deformation or elongation. Ductility is defined as the distance in $\mathrm{cm}$, to which a standard sample or briquette of the material will be elongated without breaking.

Equipment used: Mould no. 2, 4, 8, Petroleum jelly, locking nuts, Ductility machine, Vubricant oil, Water, 80/100 penetration grade asphalt, metal pin, diesel and cotton, Refrigerator, Blade and knife.

\section{B. Preparation to Make Crumb Rubber Modified Bitumen Blend}

In preparing the modified binders, about $500 \mathrm{gm}$ of the bitumen was heated to a fluid condition in a 1.5litre capacity metal container. For the blending of crumb rubber with bitumen, it was heated to a temperature of $160{ }^{\circ} \mathrm{C}$ and then crumb rubber was added. For each mixture sample $0 \%, 8 \%$, $10 \%, 12 \%$, and $14 \%$ of crumb rubber by weight is used. The blend is mixed manually for about 3-4 minutes. The mixture is then heated to $160{ }^{\circ} \mathrm{C}$ and the whole mass was stirred using a mechanical stirrer for about 50 minutes. Care is taken to maintain the temperature between $160{ }^{\circ} \mathrm{C}$ to $170{ }^{\circ} \mathrm{C}$. The contents are gradually stirred for about 55 minutes. The modified bitumen is cooled to room temperature and suitably stored for testing.

\section{Readings}

TABLE I

PENETRATION AND DUCTILITY TEST RESULTS

\begin{tabular}{|c|c|c|}
\hline Sample & Penetration Value (1/10th of mm) & Ductility Value(cm) \\
\hline Bitumen & 75 & 20 \\
\hline PB + 4\% CR & 48 & 18.6 \\
\hline PB + 6\% CR & 55 & 18 \\
\hline PB + 8\% CR & 68 & 17.5 \\
\hline PB + 10\% CR & 85 & 17.1 \\
\hline
\end{tabular}




\section{CONCLUSION}

The objective of the study was to utilize the waste materials i.e. crumb rubber waste for mass scale utilization such as in highway construction in an environmentally safe manner.

The bitumen of grade 80/100 was taken and it was modified with different percentage of crumb rubber starting from $4 \%$ to $12 \%$. From the results, the maximum percentage of crumb rubber as bitumen modifier was in the range 10 $12 \%$ by the weight of binder content.

It was observed that values of penetration and ductility are reduced by $14.56 \%$ and $24.49 \%$ respectively, by the addition of $12 \%$ crumb rubber waste.

Overall, using the crumb rubber in bituminous mixture helps to:

- Utilization of crumb rubber waste.

- Reduction in the use of bitumen by around $10 \%$.

- Increase in the strength and performance of the road.

- Provide better adhesion between the asphalt and the aggregate.

- Avoid the use of anti-stripping agents.

- Reduce the cost.

- Avoid disposal of crumb rubber waste by incineration and land filling.

\section{ACKNOWLEDGMENT}

I express my heartily gratitude towards our Head of Department for his personal involvement and constructive criticism provided beyond technical guidance during the course of the preparation of the report. He has been keen enough for providing us with the valuable suggestions from time to time. Above all, his keen interest in the seminar helped us to come out with the best.

Thanks to Dr. S. M. Pore, of Civil Engineering Department, Dr. Babasaheb Ambedkar Technological University, Lonere for encouragement and providing necessary information. I was ending this acknowledgement with deep indebtedness to Prof. S. V. Bhise, all the other faculty members, and our friends who have helped us directly or indirectly for completing this manuscript.

\section{REFERENCES}

[1] Anusha G Krishna; International Journal of Applied Engineering Research ISSN 0973-4562 Volume 13, Number 7 (2018) pp. 135138

[2] Azam Khan, Mahmood Omar Imam and Anupom Deb Roy, Proceedings of the $4^{\text {th }}$ International Conference on Civil Engineering for Sustainable Development (ICCESD 2018), 9 11 February 2018 , KUET, Khulna, Bangladesh (ISBN-978-984-34-3502-6)

[3] Deshmukh Nitu .H, Kshirsagar D. Y; International Journal of Advance Research and Development.

[4] Hanumantharao, C, Anil Pradhyumna, T., Durga Prasad, K.,NaveenKumar, N., Shantha Kumar Reddy, G., Hemanth Vardhan, M; International Journal of Recent Technology and Engineering (IJRTE) ISSN: 2277-3878, Volume-8, Issue-1, May 2019

[5] International Conference on Civil Engineering for Sustainable Development (ICCESD 2018)

[6] JENISH.J.L, MOHAMED ISAQ.S, ELAYA BHARATHI.C, MOHIDEEN ASBAR.I; IJARIIE-ISSN(O)-2395-4396

[7] Miss. Mane Priyanka Arun, Mr. Petkar Deepak Ganesh, Mr. Bhosale S.M.; International Journal of Scientific and Research Publications, Volume 3, Issue 9, September 2013

[8] Niraj D. Baraiya; International Journal of Application or Innovation in Engineering \& Management (IJAIEM)

[9] Nuha S. Mashaan, Asim H. Ali, Mohamed Rehan Karim and Mahrez Abdelaziz International Journal of the Physical Sciences vol. 6(4), pp. 684-690, 18 February, 2011

[10] Nuha S. Mashaan, Asim Hassan Ali, Mohamed Rehan Karim and Mahrez Abdelaziz; International Journal of the Physical Sciences Vol. 7(2), pp. 166 - 170, 9 January, 2012

[11] Parmeet Singh, Akash Pathania, Abhishek Gupta, Deepak Kumar, Kamalpreet Singh, Devinder Angurana, Abhishek Sharma, Bhrigu Sharma, Dr. Arvind Dewangan, Er. Khushwace Singh; Internationa Journal of Engineering Research And Management (IJERM) ISSN: 2349-2058, Volume-05, Issue-05, May 2018

[12] Rokade S; 2012 International Conference on Future Environment and Energy IPCBEE vol.28(2012) (C) (2012)IACSIT Press, Singapore

[13] Sharma Pavan Kumar, Saxena Anil Kumar, Arora T.R.; International Journal of Engineering Research \& Technology (IJERT), ISSN 2278-0181 .Vol. 2 Issue 8, August - 2013

[14] V. Suganpriya, S. Omprakash, V. Chandralega; International Journal of Engineering Research \& Technology (IJERT) 